\title{
Effect of Internet-Based Rehabilitation Programs on Improvement of Pain and Physical Function in Patients with Knee Osteoarthritis: Systematic Review and Meta-analysis of Randomized Controlled Trials
}

Su-Hang Xie ${ }^{1,2,3^{*}}$, PT, MM; Qian Wang ${ }^{1,2,3^{*}}, \mathrm{MD}$, PhD; Li-Qiong Wang ${ }^{1,2,3}$, PT, PhD; Lin Wang ${ }^{1,2,3}$, PT, MM; Kang-Ping Song ${ }^{1,2,3}$, PT, MM; Cheng-Qi He ${ }^{2,3}$, MD, PhD

\footnotetext{
${ }^{1}$ School of Rehabilitation Sciences, West China School of Medicine, Sichuan University, Chengdu, Sichuan, China

${ }^{2}$ Rehabilitation Medicine Center, West China Hospital, Sichuan University, Chengdu, Sichuan, China

${ }^{3}$ Key Laboratory of Rehabilitation Medicine in Sichuan Province, Chengdu, Sichuan, China

* these authors contributed equally
}

Corresponding Author:

Cheng-Qi He, MD, PhD

Rehabilitation Medicine Center

West China Hospital

Sichuan University

No 37 Guoxue Street

Wuhou District

Chengdu, Sichuan, 610041

China

Phone: 862885422847

Fax: 862885423819

Email: hxkfhcq2015@126.com

\section{Abstract}

Background: Osteoarthritis (OA) is a chronic, debilitating, and degenerative joint disease. However, it is difficult for patients with knee OA to access conventional rehabilitation when discharging from the hospital. Internet-based rehabilitation is one of the promising telemedicine strategies to provide a means combining monitoring, guidance, and treatment for patients with knee OA.

Objective: The aim of this study was to conduct a systematic review and meta-analysis for assessing the effect of internet-based rehabilitation programs on pain and physical function in patients with knee OA.

Methods: Keywords related to knee OA and internet-based rehabilitation were systematically searched in the Web of Science, MEDLINE, EMBASE, CENTRAL, Scopus, PEDro (Physiotherapy Evidence Database), CNKI, SinoMed, and WANFANG databases from January 2000 to April 2020. Only randomized controlled trials were included. The authors independently screened the literature. The main outcome measures were focused on pain and physical function. A meta-analysis was performed on the collected data. Review Manager (RevMan, version 5.3) was used for all analyses.

Results: The systematic review identified 6 randomized controlled trials, 4 of which were included in the meta-analysis, comprising a total of 791 patients with knee OA. The meta-analysis with the fixed-effects model showed that the internet-based rehabilitation programs could significantly alleviate the osteoarthritic pain for patients compared with conventional rehabilitation (standardized mean difference [SMD] $-0.21,95 \% \mathrm{CI}-0.4$ to $-0.01, P=.04$ ). No significant difference was found in the improvement of physical function in patients with knee OA compared with conventional rehabilitation within 2 to 12 months (SMD -0.08, $95 \%$ CI -0.27 to $0.12, P=.43)$.

Conclusions: This systematic review shows that internet-based rehabilitation programs could improve the pain but not physical function for patients with knee OA. However, there was a very small number of studies that could be included in the review and meta-analysis. Thus, further studies with large sample sizes are warranted to promote the effectiveness of internet-based rehabilitation and to develop its personalized design. 
(J Med Internet Res 2021;23(1):e21542) doi: 10.2196/21542

\section{KEYWORDS}

internet-based rehabilitation; knee; osteoarthritis; pain; physical function; meta-analysis; review; telerehabilitation; eHealth; telemedicine

\section{Introduction}

Osteoarthritis (OA) is a chronic, debilitating, and degenerative joint disease, which is widely considered as a significant threat to healthy aging [1-3]. A recent estimation revealed that approximately 250 million individuals are suffering from OA worldwide, and the knee joint is the most frequently affected joint with an incidence of $16 \%-17 \%$ among people aged 50 to 75 years $[4,5]$. Chronic pain and impaired physical function are recognized as the main issues affecting quality of life for patients with knee OA [6,7]. Physical therapy is one of the effective methods that is commonly prescribed for patients with knee $\mathrm{OA}$ to alleviate pain and improve physical function [8-10]. However, it is difficult for patients with knee OA, who are mainly middle-aged to elderly, to access conventional rehabilitation programs that are monitored and guided by physicians or therapists when discharging from the hospital [4]. Thus, it is necessary to develop telerehabilitation strategies to provide the opportunity to access professional rehabilitation programs and guides for improving the long-term outcomes of pain and physical function for patients with knee OA.

The advent of telemedicine has facilitated the access of patients to real-time communication with professional physicians or therapists [11-13]. Telerehabilitation has been developed in the fields of physical medicine and rehabilitation to support continuous rehabilitation services for patients with disabilities [14]. Several types of telerehabilitation services have been proposed, including video conference, telephone conference, and web-based knowledge platforms [15-17]. Of these, internet-based rehabilitation, which combines internet technologies with physical medicine and rehabilitation, could vastly promote accessibility to professional physicians or therapists for patients, even for those residing in remote areas $[18,19]$. The feasibility of internet-based rehabilitation and its effect have been investigated in patients with stroke [20,21], chronic obstructive pulmonary disease [22-25], Parkinson disease [26-28], multiple sclerosis [29,30] and following knee arthroplasty [31,32].

Despite the increasing popularity of these internet-based rehabilitation programs, there is insufficient evidence to demonstrate their effectiveness for patients with knee OA. Positive results have been shown in some studies in which specific programs of internet-based rehabilitation could improve pain and physical function for patients with knee OA as compared with conventional rehabilitation [33,34]. However, different views have also been put forth, indicating no significant change in OA-related pain and physical function during long-term follow up of 12 months [35,36]. To our knowledge, there has been no meta-analysis of randomized controlled trials (RCTs) assessing the effects of internet-based rehabilitation programs on improvement of pain and physical function in patients with knee OA. Therefore, the aim of this systematic review and meta-analysis was to assess the effect of internet-based rehabilitation programs on the pain and physical function of patients with knee OA, and to evaluate the specific components (eg, exercise guidance, knee OA education) designed for each of the internet-based rehabilitation programs reported to date.

\section{Methods}

\section{Study Protocol and Registration}

All analyses were based on data from previously published studies. Thus, no ethical approval or patient consent was required. The review was conducted according to the Preferred Reporting Items for Systematic Reviews and Meta-Analyses (PRISMA) statement [37]. The a priori protocol for the review is published in the International Prospective Register of Systematic Reviews (PROSPERO): CRD42019137907.

\section{Information Sources}

The following electronic databases were searched to identify relevant studies from January 2000 to April 2020: Web of Science, MEDLINE, EMBASE, CENTRAL, Scopus, Physiotherapy Evidence Database (PEDro), CNKI, SinoMed, and WANFANG. Relevant journals, conference proceedings, and reference lists were manually searched to identify additional studies.

\section{Search and Eligibility Criteria}

\section{Overall Search Strategy}

The search was performed using a combination of the following keywords on May 1, 2020: (osteoarthritis or osteoarthrosis or cartilage or degenerative arthritis) AND (telemedicine or e-health or telehealth or telerehabilitation or internet or web or online or app or wearable or sensor) AND knee. The search strategies for each database are presented in Multimedia Appendix 1. In addition, the literature was searched manually from the reference lists of the articles identified from the search of the electronic databases. The inclusion and exclusion criteria of the studies were based on the PICO (Population, Intervention, Comparison, Outcome) method [38,39].

\section{Studies}

RCTs regarding the effect of internet-based rehabilitation programs for patients with knee OA were included in the review. The included studies were published in English or Chinese. Articles were excluded if the study was a non-RCT or nonclinical trial. Abstracts from meeting proceedings with no corresponding full article published in a peer-reviewed journal or no specific data provided even after contacting the author were excluded. 


\section{Participants}

The studies involved participants aged above 18 years, who were diagnosed with knee OA by a physician or self-reported a physician diagnosis along with matching items based on the American College of Rheumatology clinical criteria [40,41], and had not undergone knee arthroplasty.

\section{Interventions}

Studies that were included in the review compared the effects of internet-based rehabilitation programs with conventional rehabilitation (eg, rehabilitation performed in the clinic or hospital) or waiting without any therapy. Internet-based rehabilitation could be the only intervention or could be combined with another form of physiotherapy. The internet-based rehabilitation programs were performed through videos or graphic knowledge demonstrations, real-time communication with physicians or therapists, and group discussions to promote the self-rehabilitation for individuals with knee OA. Rehabilitation methods include exercise, patient education, and self-management. Interventions used for participants had to be internet-based such as by email, websites, or software systems. Studies using noninternet technology support or not explicitly stating that internet technology was used to support the intervention were excluded, such as telephone, DVD, and cable television.

\section{Outcome Measures}

The main outcome measures were focused on pain (eg, the Western Ontario and McMaster [WOMAC] pain subscale, visual analog scale [VAS], Numerical Pain Rating Scale [NPRS]) and physical function (eg, WOMAC functional subscale, 30-second chair stand test, Timed Up and Go Test [TUG], and Knee Injury and OA Outcome Score [KOOS] functional subscale) for patients with knee OA. The primary outcome scale or the most representative scale was selected for analysis if multiple scales were used to evaluate the same outcome index in a study.

\section{Search Methods for Identification of Studies}

Two authors (LW and LQW) independently reviewed the search results and screened the titles, abstracts, and full texts of identified references to select potentially eligible studies, which were imported into EndNote X8 (Clarivate Analytics, Philadelphia, PA, USA).

\section{Data Extraction and Management}

Two authors (LW and LQW) completed data extraction independently and assessed the risk of bias for the included studies. A final decision was made after discussion with authors QW and $\mathrm{CH}$ in cases of any disagreement related to the data extraction process. Finally, the data were summarized in a previously standardized worksheet of Excel for Windows 2010. When the reported data were insufficient, we contacted the authors for more information.

The extracted data included: basic information of the study (eg, first author, year of publication, country, email address of the corresponding author); risk of bias (based on the PEDro scale) [42]; participants (overall sample size and sample size for each condition, overall mean age and the mean age for each condition, and the number of men and women); type of intervention for the experimental group (name of the program, components of the program, intervention time, delivery location); type of intervention for the control group (same as above); and outcomes (eg, the WOMAC pain and functional subscale, VAS, TUG). Outcomes reported as continuous variables are presented as the mean (SD).

\section{Quality Assessment}

Quality assessments were performed with the PEDro scale [42]. The PEDro tool is based on the Delphi List criteria, which was used to evaluate the methodological quality in this study, and is considered to be valid and reliable [42-44]. All included trial reports were checked in the PEDro database to confirm their PEDro scale score. Considering that criterion 1 was not utilized to calculate the score, the sum of the other criteria could have a maximum of 10 points. Trials with a score $\geq 6$ points were classified as "good," whereas those with a score $\leq 5$ points were graded as "poor" [45]. The poor-quality studies were excluded from the analysis. The quality of studies was assessed by two authors (SX and KS) using the PEDro scale and associated notes on administration of the PEDro scale [46] independently if a score was not available in the PEDro database [47]. Any dispute was settled through discussion or with consultation of a third reviewer $(\mathrm{QW})$.

\section{Statistical Analysis}

The mean (SD) of continuous outcome variables after therapy was used to calculate the total effect size via the mean difference and $95 \%$ CI. The standardized mean difference (SMD) was calculated when studies used different methods or scales to measure the same outcome. We assessed heterogeneity visually and based on the $\mathrm{I}^{2}$ statistic [48]. The forest plots for the meta-analysis are presented along with a description of the results. A random-effects model was applied when substantial heterogeneity was observed $\left(P<.05\right.$ or $\left.\mathrm{I}^{2}>50 \%\right)$; otherwise, a fixed-effects model was used [49]. Review Manager version 5.3 (Cochrane Collaboration, Copenhagen, Denmark) was employed for the statistical analyses and to produce forest plots.

\section{Results}

\section{Search and Selection}

A total of 697 publications were retrieved through electronic searching from the databases. After exclusion of the duplicated studies and irrelevant subjects via the initial screening of titles and abstracts, 12 articles were systematically reviewed with 6 studies further excluded due to low quality based on a PEDro score $\leq 5$ points. The list of eligible studies was sent to experts in the field to confirm that no other studies could be identified. In addition, the final articles included in the systematic review and meta-analysis were determined according to the guidelines of Cochrane Handbook for Systematic Reviews of Interventions [50]. Finally, 6 studies were identified for the systematic review, 4 of which were included in the meta-analysis, involving a total of 791 patients with knee OA (Figure 1). 
Figure 1. PRISMA (Preferred Reporting Items for Systematic reviews and Meta-Analyses) flow diagram. CENTRAL: Cochrane Central Register of Controlled Trials; EMBASE: Excerpta Medica Database; MEDLINE: Medical Literature Analysis and Retrieval System Online; PEDro: Physiotherapy Evidence Database; CNKI: China National Knowledge Infrastructure.

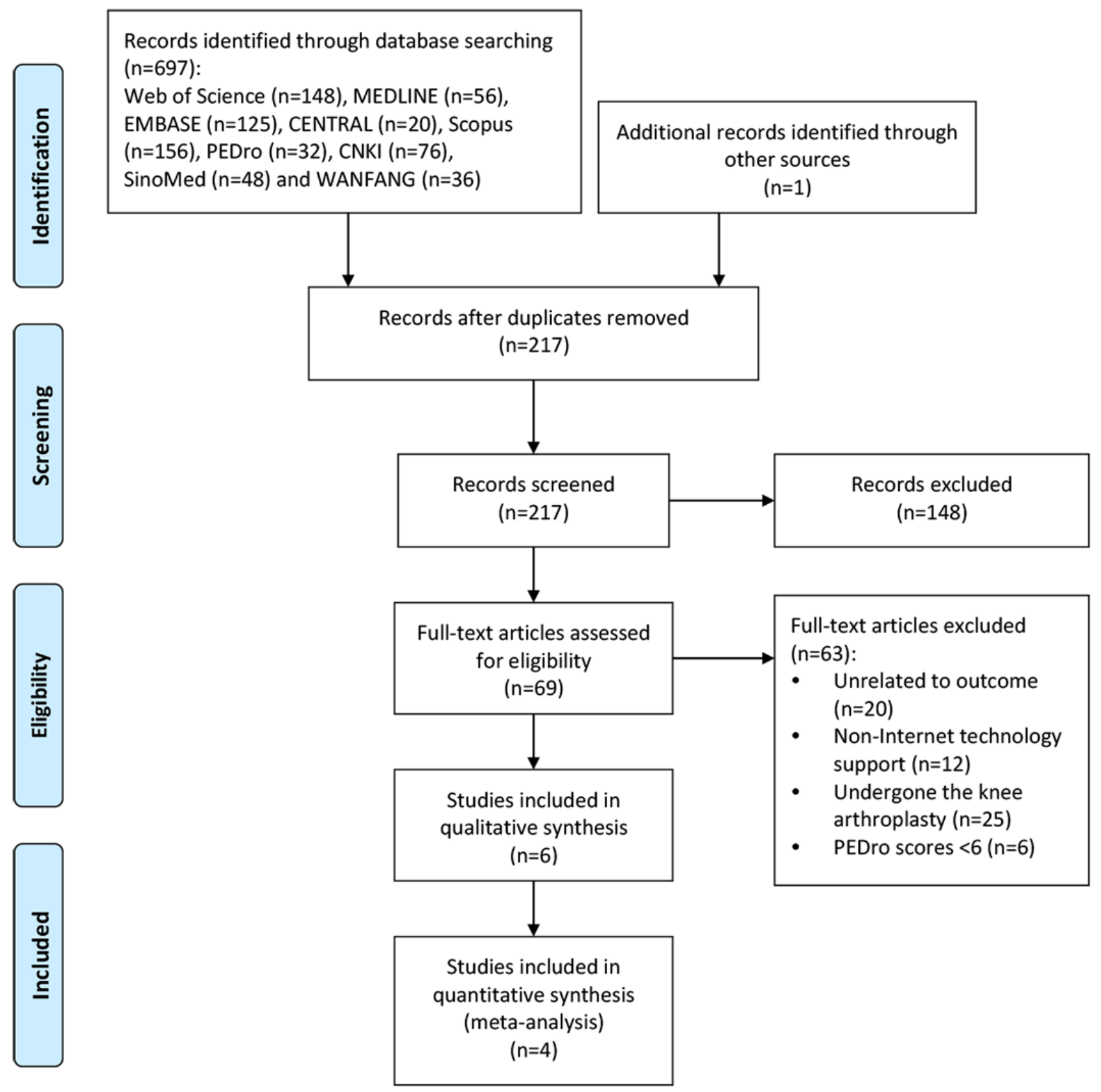

\section{Study Characteristics}

The baseline descriptive characteristics (country, sample size, age, and gender) of the 6 studies included in the systematic review are summarized in Table 1 . Two studies were from the
United States [35,51], one from Australia [33], one from China [34], one from Brazil [52], and one from the Netherlands [53].

The mean age of patients with knee OA ranged from 53.1 (SD 8.5) to 72.25 (SD 8.84) years, and all studies included both men and women. 
Table 1. Baseline descriptive characteristics of studies included in the systematic review.

\begin{tabular}{|c|c|c|c|c|c|c|}
\hline \multirow{2}{*}{$\begin{array}{l}\text { Reference, } \\
\text { year, country }\end{array}$} & \multicolumn{2}{|c|}{ Patient characteristics } & \multirow[t]{2}{*}{ Comparison } & \multirow[t]{2}{*}{ Intervention } & \multirow{2}{*}{$\begin{array}{l}\text { Intervention } \\
\text { time (weeks) }\end{array}$} & \multirow[t]{2}{*}{ Outcome } \\
\hline & $\mathrm{N}$ & $\begin{array}{l}\text { Age (years), } \\
\text { mean (SD) }\end{array}$ & & & & \\
\hline $\begin{array}{l}\text { Aily et al } \\
{[52]^{\text {a }}, 2020} \\
\text { Brazil }^{2}\end{array}$ & $\begin{array}{l}20(10 \\
\text { women, } 10 \\
\text { men) }\end{array}$ & $\begin{array}{l}\text { Group } 1(\mathrm{n}=10) \text { : } \\
54.8(8.3) ; \\
\text { Group } 2(\mathrm{n}=10) \text { : } \\
53.1(8.5)\end{array}$ & $\begin{array}{l}\text { Group 1: supervised } \\
\text { periodized circuit } \\
\text { training with load } \\
\text { progression, } 3 \text { times } \\
\text { a week }\end{array}$ & $\begin{array}{l}\text { Group 2: same exercise proto- } \\
\text { col as group } 1 \text {, but } \\
\text { orientations to the exercises } \\
\text { provided through videos on a } \\
\text { website, DVD, or YouTube }\end{array}$ & 14 & $\begin{array}{l}\mathrm{VAS}^{\mathrm{b}} \text {, WOMAC }{ }^{\mathrm{c}}, 30-\mathrm{s} \\
\text { chair stand test, } 40-\mathrm{m} \text { fast- } \\
\text { paced walk test, stair climb } \\
\text { test }\end{array}$ \\
\hline $\begin{array}{l}\text { Huang et al } \\
{[34]^{\mathrm{a}}, 2019,} \\
\text { China }\end{array}$ & $\begin{array}{l}40(30 \\
\text { women, } 10 \\
\text { men) }\end{array}$ & $\begin{array}{l}\text { Group } 1(n=20) \text { : } \\
72.25(8.84) \\
\text { Group } 2(n=20) \text { : } \\
67.25(10.97)\end{array}$ & $\begin{array}{l}\text { Group 1: convention- } \\
\text { al rehabilitation in } \\
\text { the clinic }\end{array}$ & $\begin{array}{l}\text { Group 2: conventional rehabili- } \\
\text { tation plus a brief } \mathrm{GOH}^{\mathrm{d}} \text {-based } \\
\text { intervention (educational lec- } \\
\text { tures, medical suggestions, and } \\
\text { psychotherapy) }\end{array}$ & 24 & WOMAC \\
\hline $\begin{array}{l}\text { O’Moore } \\
{[33]^{\text {a }}, 2018,} \\
\text { Australia }\end{array}$ & $\begin{array}{l}69(55 \\
\text { women, } 14 \\
\text { men) }\end{array}$ & $\begin{array}{l}\text { Group } 1(\mathrm{n}=25) \text { : } \\
59.68(6.01) \\
\text { Group } 2(\mathrm{n}=44) \text { : } \\
63.16(7.38)\end{array}$ & $\begin{array}{l}\text { Group 1: treatment } \\
\text { as usual. }\end{array}$ & $\begin{array}{l}\text { Group 2: } \mathrm{iCBT}^{\mathrm{e}} \text { program for } \\
\text { depression added to treatment } \\
\text { as usual }\end{array}$ & 10 & ASES $^{\mathrm{f}}$, WOMAC \\
\hline $\begin{array}{l}\text { Allen et al } \\
{[35]^{\mathrm{a}}, 2018} \\
\text { United } \\
\text { States }\end{array}$ & $\begin{array}{l}350(251 \\
\text { women, } 99 \\
\text { men) }\end{array}$ & $\begin{array}{l}\text { Group 1 } \\
(\mathrm{n}=140): 65.7 \\
(10.3) ; \text { Group } 2 \\
(\mathrm{n}=68): 64.3 \\
(12.2) ; \text { Group } 3 \\
(\mathrm{n}=142): 65.3 \\
(11.5)\end{array}$ & $\begin{array}{l}\text { Group 1: physiother- } \\
\text { apy (evidence-based } \\
\text { approach); Group 2: } \\
\text { wait without any } \\
\text { therapy }\end{array}$ & $\begin{array}{l}\text { Group 3: internet-based exer- } \\
\text { cise training }\end{array}$ & 48 & $\begin{array}{l}\text { WOMAC, 30-s chair stand, } \\
\text { TUG }^{\mathrm{g}}, 2 \text {-min step test, uni- } \\
\text { lateral stand time }\end{array}$ \\
\hline $\begin{array}{l}\text { Rini et al } \\
\text { [51], 2015, } \\
\text { United } \\
\text { States }\end{array}$ & $\begin{array}{l}113(91 \\
\text { women, } 22 \\
\text { men) }\end{array}$ & $\begin{array}{l}\text { Group } 1(\mathrm{n}=55) \text { : } \\
66.67(11.02) \\
\text { Group } 2(\mathrm{n}=58) \text { : } \\
68.52(7.65)\end{array}$ & $\begin{array}{l}\text { Group 1: wait with- } \\
\text { out any therapy }\end{array}$ & $\begin{array}{l}\text { Group 2: PainCOACH program } \\
\text { through the internet }\end{array}$ & $8-10$ & $\begin{array}{l}\text { AIMS } 2^{\mathrm{h}} \text { 5-item arthritis pain } \\
\text { subscale, ASES, AIMS2 } \\
\text { subscales relevant to lower } \\
\text { extremity functioning, 20- } \\
\text { item PASS }{ }^{\mathrm{i}} \text {, AIMS2 comor- } \\
\text { bidities subscale }\end{array}$ \\
\hline $\begin{array}{l}\text { Bossen et al } \\
\text { [53], 2013, } \\
\text { Netherlands }\end{array}$ & $\begin{array}{l}199(129 \\
\text { women, } 70 \\
\text { men) }\end{array}$ & $\begin{array}{l}\text { Group 1 }(\mathrm{n}=99) \text { : } \\
63.0(5.4) ; \\
\text { Group 2 } \\
(\mathrm{n}=100): 61.0 \\
(5.9)\end{array}$ & $\begin{array}{l}\text { Group 1: waitlist } \\
\text { control without any } \\
\text { therapy }\end{array}$ & $\begin{array}{l}\text { Group 2: Join } 2 \text { move, a fully } \\
\text { automated web-based interven- } \\
\text { tion without human support }\end{array}$ & 48 & $\begin{array}{l}\text { Self-reported PA }{ }^{\mathrm{j}} \text { PASE }^{\mathrm{k}} \\
\text { and ActiGraph GT3X triaxi- } \\
\text { al accelerometers), KOOS } \\
\text { (functional subscale), self- } \\
\text { perceived effect, NRS }{ }^{\mathrm{m}} \text {, } \\
\text { ASES }\end{array}$ \\
\hline
\end{tabular}

\footnotetext{
${ }^{\mathrm{a}}$ Included in the meta-analysis.

${ }^{b}$ WOMAC: Western Ontario and McMaster Universities Osteoarthritis index.

${ }^{\mathrm{c}}$ VAS: visual analog scale.

${ }^{\mathrm{d}} \mathrm{GOH}$ : Guangdong Online Hospital.

$\mathrm{e}_{\mathrm{iCBT}}$ : internet cognitive behavior therapy.

${ }^{f}$ ASES: Arthritis Self Efficacy Scale.

${ }^{\mathrm{g}}$ TUG: Timed Up and Go Test.

h AIMS2: Arthritis Impact Measurement Scale 2.

${ }^{\mathrm{i}}$ PASS: Pain Anxiety Symptoms Scale.

${ }^{\mathrm{j}} \mathrm{PA}$ : physical activity.

${ }^{k}$ PASE: Physical Activity Scale for the Elderly.

${ }^{1}$ KOOS: Knee Injury and Osteoarthritis Outcome Score.

$\mathrm{m}_{\mathrm{NRS}}$ : numeric rating scale.
}

\section{Intervention Programs}

The internet-based rehabilitation programs used in the included RCTs are summarized in Table 1. Various internet-based rehabilitation programs have been developed in the included studies. To promote physical fitness, Allen et al [35] from the
United States developed an internet-based exercise training program (IBET) containing tailored exercises, exercise progression, video demonstrations, automated reminders, and guidance on progression for patients with OA. Participants were encouraged to complete strengthening and stretching exercises at least 3 times per week and to engage in aerobic exercises 
daily [35]. Similarly, Rini et al [51] from the United States developed the PainCOACH program, which is a web-based platform that offers physical, psychological, and occupational therapies. PainCOACH includes 8 modules related to cognitive or behavioral pain coping skills in a self-directed manner (eg, without therapist contact) at a frequency of one per week. Each module took 35 to 45 minutes to complete [51]. Huang and colleagues [34] from China developed an internet-based rehabilitation program for patients with knee OA comprised of three broad segments: encouragement, educational lectures, and medical issues, each of which could be completed within 20-30 min in an independent manner. In Australia, O'Moore and colleagues [33] studied the effectiveness of an internet-based cognitive-behavioral therapy (iCBT) program for older adults with knee OA. The iCBT Sadness Program consists of six online lessons assigned as regular homework and provides access to supplementary resources. Aily and colleagues [52] from Brazil allowed patients with knee OA to utilize a website or YouTube videos for rehabilitation at home 3 times a week. They also provided periodic telephone calls to motivate, clarify, and monitor the performance of patients. In addition, a behavior-graded activity program named Join2move was developed by Bossen et al [53] in the Netherlands with the aim of promoting the self-management of behaviors of patients with knee OA when they are at home or in the community setting. The intervention period ranged from 8-10 weeks [51] to 48 weeks [35,53] (Table 1).

\section{Risk of Bias}

All 6 studies included in the review scored greater than 6 points on the PEDro scale (Table 2). Even though the greatest risk of bias lies in the nonblinding of participants, in general, the total score of the 6 studies showed high methodological rigor [54,55] despite the fact that all studies had inadequate blinding of participants and therapists, and 2 studies had inadequate blinding of outcome assessors. One study did not provide adequate follow up. Two studies did not perform an intention-to-treat analysis. Overall, the methodological quality of the included studies was assessed as "good."

Table 2. Assessment of methodological quality using the PEDro scale.

\begin{tabular}{|c|c|c|c|c|c|c|}
\hline Quality metric & Aily et al [52] & Huang et al [34] & O'Moore et al [33] & Allen et al [35] & Rini et al [51] & Bossen et al [53] \\
\hline Eligibility criteria & Yes & Yes & Yes & Yes & Yes & Yes \\
\hline Random allocation & Yes & Yes & Yes & Yes & Yes & Yes \\
\hline Concealed allocation & Yes & Yes & Yes & Yes & Yes & Yes \\
\hline Baseline comparability & Yes & Yes & Yes & Yes & Yes & Yes \\
\hline Blinded subjects & No & No & No & No & No & No \\
\hline Blinded therapists & No & No & No & No & No & No \\
\hline Blinded assessors & No & Yes & Yes & Yes & Yes & No \\
\hline Adequate follow up & Yes & Yes & Yes & Yes & Yes & No \\
\hline Intention-to-treat analysis & No & No & Yes & Yes & Yes & Yes \\
\hline Between-group comparisons & Yes & Yes & Yes & Yes & Yes & Yes \\
\hline Point estimates and variability & Yes & Yes & Yes & Yes & Yes & Yes \\
\hline Total score ${ }^{\mathrm{a}}$ & 6 & 7 & 8 & 8 & 8 & 6 \\
\hline Quality assessment & Good & Good & Good & Good & Good & Good \\
\hline
\end{tabular}

${ }^{\text {a}}$ Eligibility criteria did not contribute to the total score: $1=$ yes, $0=$ no.

\section{Outcomes of Interest}

\section{Pain}

Pain is the most disabling symptom for patients with knee OA [5]. Six studies included in the review evaluated the effect of internet-based rehabilitation on osteoarthritic pain. The WOMAC pain subscale was used in 4 studies [33-35,52], with scores on the pain subscale ranging from 0 (no dysfunction) to 20 (maximum dysfunction) based on a 5-point Likert format, or ranging from 0 (no dysfunction) to 50 (maximum dysfunction) with the 11-box numerical rating scale format [56]. In the study of Aily et al [52], the WOMAC and VAS were both used to assess pain. The VAS is a $100-\mathrm{mm}$ line and the participants are required to place a mark between the left side (0, representing "no pain") and the right side (100, representing "the worst pain imaginable"). The 10-NPRS and the Arthritis Impact Measurement Scale 2 (AIMS2) were used in the other two studies, respectively $[51,53]$. The NPRS is scored in a similar manner to the VAS, except that the NPRS is scored from 0 to 10 ( 0 means no pain and 10 means the worst possible pain). AIMS2 is comprised of a 5-item arthritis pain subscale indicating the severity of arthritis pain (1 means severe and 5 means none) and the frequency of severe pain [57]. A study that did not apply the WOMAC function subscale measures showed a significant improvement in patients with knee OA after 3 months of internet-based rehabilitation based on the NPRS, but no significant change was observed after 12 months compared with the control group [53]. In another study using the AIMS2 pain subscale, the pain after 8-10 weeks of internet-based rehabilitation was found to be significantly improved in women but not in men compared with that of the control group [51]. 
The meta-analysis on the effect of internet-based rehabilitation on osteoarthritic pain as measured by the WOMAC pain subscale contained 4 independent studies, involving a total of 411 participants [33-35,52]. We did not find evidence of significant heterogeneity among these studies $\left(\mathrm{I}^{2}=0 \%, P=.77\right)$; therefore, a fixed-effects model was used. The meta-analysis showed that internet-based rehabilitation could significantly reduce the pain of patients with knee OA compared with conventional rehabilitation as assessed by the WOMAC pain subscale (SMD $-0.21,95 \%$ CI -0.4 to $-0.01, P=.04$; Figure 2 ).

Figure 2. Forest plot of included studies comparing the effect of the internet-based intervention and conventional rehabilitation on pain according to the Western Ontario and McMaster Universities Osteoarthritis (WOMAC) pain subscale.

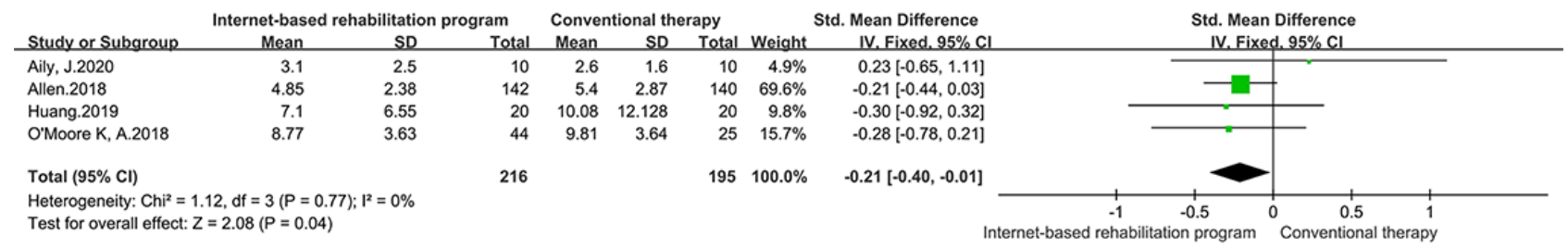

\section{Physical Function}

Improving patients' functional conditions is the objective of rehabilitation for patients with knee OA. Physical function was assessed in 4 studies using the WOMAC function subscale [33-35,52]. The total score of the WOMAC function subscale (17 items) ranges from 0 (no dysfunction) to 68 (maximum dysfunction) with a 5-point Likert response format or from 0 (no dysfunction) to 170 (maximum dysfunction) with the 11-box numerical rating scale format [56]. One study assessed physical function using the KOOS function subscale [53]. The KOOS is a self-administered questionnaire to assess functional status regarding the patient's knee problems on a 5-point Likert scale [58]. In another study, the AIMS2 subscales were used to evaluate the function of the lower extremities [51]. The TUG, 40-meter fast-paced walk test, 2-minute step test, unilateral stand time, and 30-second chair stand test were used to assess physical function for patients with knee OA in two studies
$[35,52]$. The studies that did not apply the WOMAC function subscale measures showed that internet-based rehabilitation could not significantly improve physical function compared with the control group [35,52], even compared with the waitlist group as a control [35]. Only one study suggested that the physical function could be significantly improved after 3 months of internet-based rehabilitation compared with the waitlist group. However, the beneficial effect did not last after 12 months [53].

The 4 studies included in the meta-analysis on the effect of internet-based rehabilitation on function as measured by the WOMAC function subscale involved a total of 411 participants [33-35,52]. The fixed-effects model was used in this analysis owing to the low heterogeneity $\left(\mathrm{I}^{2}=0 \%, P=.71\right)$. The results indicated that internet-based rehabilitation could not significantly improve the physical function of patients with knee OA compared with the control group according to the WOMAC function subscale (SMD $-0.08,95 \% \mathrm{CI}-0.27$ to $0.12, P=.43$; Figure 3).

Figure 3. Forest plot of included studies comparing the effect of the internet-based intervention and conventional rehabilitation on physical function based on the Western Ontario and McMaster Universities Osteoarthritis (WOMAC) function subscale.

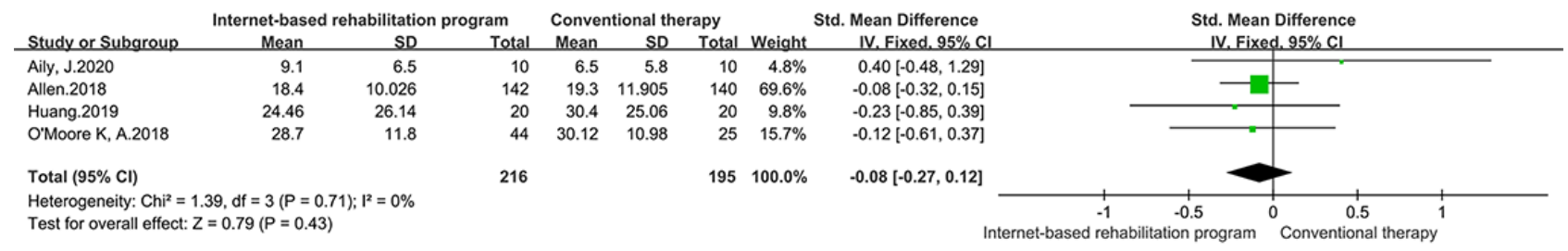

\section{Discussion}

\section{Principal Findings}

This systematic review and meta-analysis investigated whether internet-based rehabilitation programs could effectively improve the pain and physical function in patients with knee OA. The findings showed that internet-based rehabilitation could significantly improve the pain of patients with knee OA but not the physical function. Qualitative synthesis was performed for 6 studies and the meta-analysis was performed for 4 studies, comprising a total of 791 patients with knee OA. These trials showed good methodological quality as assessed by high PEDro scores $(>6)$. However, only a very small number of studies could be included in the review.
Knee OA often causes pain, which is a significant reason for patients to be admitted to the hospital. This meta-analysis showed that internet-based rehabilitation could assist patients with knee OA to self-manage and even relieve their pain after they are discharged from the hospital. The programs such as IBET and the web-based intervention Join2move were demonstrated to be effective for pain reduction in patients with knee OA [35,53]. The IBET program focused on exercise interventions tailored to patients' needs, and played a role in pain control [35]. Similarly, Join2move, developed by Bossen and colleagues [53], adopts a behavior-graded activity program to assist patients with OA to gradually increase their daily activities in a fixed amount of time [53]. These internet-based rehabilitation programs could combine various interventions based on the patient's behavioral, psychological, family, and 
social factors, which can be carried out at home or in the community setting to alleviate osteoarthritic pain.

Furthermore, knee OA could lead to the decline of patients' physical function such as walking, shopping, and housework [59]. This meta-analysis showed that internet-based rehabilitation could not significantly improve the physical function of patients with knee OA compared with conventional rehabilitation. Allen et al [35] reported that patients who underwent 12 months of internet-based strengthening and stretching exercises at least 3 times per week did not obtain a significant improvement of physical function compared with those who received conventional rehabilitation through face-to-face supervised exercise. Even though the patients' physical function could be improved after 3 months of the Join2move internet-based rehabilitation, the positive effects were not detectable at follow up of 12 months compared with the waitlist group [53]. It was postulated that the undetectable improvement after internet-based rehabilitation might be due to the fact that the recruited participants often had better baseline physical function and could accomplish the tasks assigned by the programs $[60,61]$. Alternatively, we also speculate that functional improvement may require a longer-term intervention and more intervention forms that can integrate daily life factors and improve lifestyle function, rather than simply the external exercise components. These results are comparable with the results of other meta-analyses [62,63]. Wang et al [62] showed that a telerehabilitation program (eg, telephone counseling/coaching, video conferencing) could be effective for pain control but not for functional improvement in patients after knee OA replacement surgery. Another systematic review also showed that the improvements in physical function were not significant for patients with knee OA through telerehabilitation exercise compared with either control or waitlist groups [63].

It is critical for the designers or health care providers to develop appropriate modules comprised in the internet-based rehabilitation programs. In this systematic review, we found that the programs for knee OA possessed some common modules such as exercise guidance, psychological intervention, knee OA education, and cognitive behavior management. In addition, the different programs were manifested through the specific modules. For example, the PainCOACH program focused on the behavioral and cognitive management of pain control for patients with knee OA, whereas the Join2move program aimed to enhance the physical function $[51,53]$. In the future, comprehensive and personalized modules will need to be developed to achieve the integration of facilities and patients in the community or home setting, and to monitor the safety and progress via wearable devices when performing exercises or behavior management for patients with knee OA. The modules designed for each individual can be personalized based on big data analysis collected from the wearable devices.

\section{Limitations}

There are several limitations to this study. First, there were only 6 studies that could be included in the systematic review and only 4 studies that were eligible to be included in the meta-analysis. Thus, more high-quality RCTs with larger sample sizes in this field are needed. Second, the included participants were mainly patients with knee OA who had not undergone arthroplasty or other surgical interventions. Third, the outcome measures used to assess pain and physical function included in the studies of internet-based rehabilitation were subjective. Fourth, analyses of moderator variables on the effects of the internet-based rehabilitation programs (eg, age, gender, sample size) were not performed. Fifth, considering the diversity of outcome indicators and the small number of included studies, only the studies using the WOMAC scale were included in the meta-analysis to ensure the reliability of the study and comparison. We plan to update this systematic review and meta-analysis with the increase of research on internet-based rehabilitation for knee OA in the future. Finally, only 2 studies included a follow-up period of 12 months, indicating a lack of assessments on the long-term effects of internet-based rehabilitation.

\section{Conclusion}

Internet-based rehabilitation is a promising strategy for patients with knee OA to obtain access to rehabilitation guidance and monitoring at home or in the community setting. The results of this systematic review and meta-analysis indicate that internet-based rehabilitation programs involving personalized modules could improve the pain but not the physical function of patients with knee OA compared with conventional rehabilitation. More high-quality studies with large samples are needed, with a focus on the long-term outcomes of internet-based rehabilitation for patients with knee OA.

\section{Acknowledgments}

The authors would like to acknowledge the contributions of two postdoctoral fellows at the Department of Rehabilitation Medicine and Physiotherapy from Sichuan University, Siyi Zhu and Yi Li, for assisting with the literature search and acquisition of articles, and for providing advice on statistical analysis for this systematic review. We extend special thanks to Diya Yang for her encouragement and assistance in the writing of the manuscript. This study was supported by grants from the National Natural Science Foundation of China (81572236) and the Post-Doctoral Research Project (2018HXBH080) of West China Hospital of Sichuan University. These funding sources were not involved in the literature review, systematic review, meta-analysis, and writing of the report.

\section{Conflicts of Interest}

None declared. 


\section{Multimedia Appendix 1}

Search strategy.

[DOCX File, 17 KB-Multimedia Appendix 1]

\section{References}

1. GBD 2017 DALYsHALE Collaborators. Global, regional, and national disability-adjusted life-years (DALYs) for 359 diseases and injuries and healthy life expectancy (HALE) for 195 countries and territories, 1990-2017: a systematic analysis for the Global Burden of Disease Study 2017. Lancet 2018 Nov 10;392(10159):1859-1922 [FREE Full text] [doi: 10.1016/S0140-6736(18)32335-3] [Medline: 30415748]

2. Briggs AM, Cross MJ, Hoy DG, Sànchez-Riera L, Blyth FM, Woolf AD, et al. Musculoskeletal Health Conditions Represent a Global Threat to Healthy Aging: A Report for the 2015 World Health Organization World Report on Ageing and Health. Gerontologist 2016 Apr;56(Suppl 2):S243-S255. [doi: 10.1093/geront/gnw002] [Medline: 26994264]

3. Bowden JL, Hunter DJ, Deveza LA, Duong V, Dziedzic KS, Allen KD, et al. Core and adjunctive interventions for osteoarthritis: efficacy and models for implementation. Nat Rev Rheumatol 2020 Aug;16(8):434-447. [doi: 10.1038/s41584-020-0447-8] [Medline: $\underline{\text { 32661322] }}$

4. Prieto-Alhambra D, Judge A, Javaid MK, Cooper C, Diez-Perez A, Arden NK. Incidence and risk factors for clinically diagnosed knee, hip and hand osteoarthritis: influences of age, gender and osteoarthritis affecting other joints. Ann Rheum Dis 2014 Sep;73(9):1659-1664 [FREE Full text] [doi: 10.1136/annrheumdis-2013-203355] [Medline: 23744977]

5. Hunter DJ, Bierma-Zeinstra S. Osteoarthritis. Lancet 2019 Apr 27;393(10182):1745-1759. [doi: 10.1016/S0140-6736(19)30417-9] [Medline: 31034380]

6. Murphy LB, Sacks JJ, Brady TJ, Hootman JM, Chapman DP. Anxiety and depression among US adults with arthritis: prevalence and correlates. Arthritis Care Res (Hoboken) 2012 Jul;64(7):968-976. [doi: 10.1002/acr.21685] [Medline: 22550055]

7. Cross M, Smith E, Hoy D, Nolte S, Ackerman I, Fransen M, et al. The global burden of hip and knee osteoarthritis: estimates from the global burden of disease 2010 study. Ann Rheum Dis 2014 Jul;73(7):1323-1330. [doi:

10.1136/annrheumdis-2013-204763] [Medline: 24553908]

8. de Rooij M, van der Leeden M, Cheung J, van der Esch M, Häkkinen A, Haverkamp D, et al. Efficacy of Tailored Exercise Therapy on Physical Functioning in Patients With Knee Osteoarthritis and Comorbidity: A Randomized Controlled Trial. Arthritis Care Res (Hoboken) 2017 Jun;69(6):807-816. [doi: 10.1002/acr.23013] [Medline: 27563831]

9. Zhang W, Moskowitz RW, Nuki G, Abramson S, Altman RD, Arden N, et al. OARSI recommendations for the management of hip and knee osteoarthritis, Part II: OARSI evidence-based, expert consensus guidelines. Osteoarthritis Cartilage 2008 Feb;16(2):137-162 [FREE Full text] [doi: 10.1016/j.joca.2007.12.013] [Medline: 18279766 ]

10. Bannuru RR, Osani MC, Vaysbrot EE, Arden NK, Bennell K, Bierma-Zeinstra SMA, et al. OARSI guidelines for the non-surgical management of knee, hip, and polyarticular osteoarthritis. Osteoarthritis Cartilage 2019 Nov;27(11):1578-1589 [FREE Full text] [doi: 10.1016/j.joca.2019.06.011] [Medline: 31278997]

11. Rosen MJ. Telerehabilitation. Telemed J E Health 2004;10(2):115-117. [doi: 10.1089/tmj.2004.10.115] [Medline: 15319039]

12. Committee on Evaluating Clinical Applications of Telemedicine. In: Field MJ, editor. Telemedicine: A Guide to Assessing Telecommunications in Health Care. Washington DC: National Academies Press; 1996:136-137.

13. Odole AC, Ojo OD. A Telephone-based Physiotherapy Intervention for Patients with Osteoarthritis of the Knee. Int J Telerehabil 2013;5(2):11-20 [FREE Full text] [doi: 10.5195/ijt.2013.6125] [Medline: 25945214]

14. Burns RB, Crislip D, Daviou P, Temkin A, Vesmarovich S, Anshutz J, et al. Using telerehabilitation to support assistive technology. Assist Technol 1998;10(2):126-133. [doi: 10.1080/10400435.1998.10131970] [Medline: 10339280]

15. Lee AC, Davenport TE, Randall K. Telehealth Physical Therapy in Musculoskeletal Practice. J Orthop Sports Phys Ther 2018 Oct;48(10):736-739. [doi: 10.2519/jospt.2018.0613] [Medline: 30270782]

16. Russell TG. Physical rehabilitation using telemedicine. J Telemed Telecare 2007;13(5):217-220. [doi: 10.1258/135763307781458886] [Medline: 17697506$]$

17. Galea MD. Telemedicine in Rehabilitation. Phys Med Rehabil Clin N Am 2019 May;30(2):473-483. [doi: 10.1016/j.pmr.2018.12.002] [Medline: 30954160]

18. Burridge JH, Lee ACW, Turk R, Stokes M, Whitall J, Vaidyanathan R, et al. Telehealth, Wearable Sensors, and the Internet: Will They Improve Stroke Outcomes Through Increased Intensity of Therapy, Motivation, and Adherence to Rehabilitation Programs? J Neurol Phys Ther 2017 Jul;41(Suppl 3):S32-S38. [doi: 10.1097/NPT.0000000000000183] [Medline: 28628594]

19. Hallensleben C, van Luenen S, Rolink E, Ossebaard HC, Chavannes NH. eHealth for people with COPD in the Netherlands: a scoping review. Int J Chron Obstruct Pulmon Dis 2019;14:1681-1690. [doi: 10.2147/COPD.S207187] [Medline: 31440044]

20. Tchero H, Tabue Teguo M, Lannuzel A, Rusch E. Telerehabilitation for Stroke Survivors: Systematic Review and Meta-Analysis. J Med Internet Res 2018 Oct 26;20(10):e10867 [FREE Full text] [doi: 10.2196/10867] [Medline: 30368437]

21. Sarfo FS, Adamu S, Awuah D, Sarfo-Kantanka O, Ovbiagele B. Potential role of tele-rehabilitation to address barriers to implementation of physical therapy among West African stroke survivors: A cross-sectional survey. J Neurol Sci 2017 Oct 15;381:203-208 [FREE Full text] [doi: 10.1016/j.jns.2017.08.3265] [Medline: 28991682] 
22. Zanaboni P, Dinesen B, Hjalmarsen A, Hoaas H, Holland AE, Oliveira CC, et al. Long-term integrated telerehabilitation of COPD Patients: a multicentre randomised controlled trial (iTrain). BMC Pulm Med 2016 Aug 22;16(1):126 [FREE Full text] [doi: 10.1186/s12890-016-0288-z] [Medline: 27549782]

23. Paneroni M, Colombo F, Papalia A, Colitta A, Borghi G, Saleri M, et al. Is Telerehabilitation a Safe and Viable Option for Patients with COPD? A Feasibility Study. COPD 2015 Apr;12(2):217-225. [doi: 10.3109/15412555.2014.933794] [Medline: 25093419]

24. Holland AE, Cox NS. Telerehabilitation for COPD: Could pulmonary rehabilitation deliver on its promise? Respirology 2017 May;22(4):626-627. [doi: 10.1111/resp.13028] [Medline: 28345290]

25. Tabak M, Vollenbroek-Hutten MM, van der Valk PD, van der Palen J, Hermens HJ. A telerehabilitation intervention for patients with Chronic Obstructive Pulmonary Disease: a randomized controlled pilot trial. Clin Rehabil 2014 Jun;28(6):582-591. [doi: 10.1177/0269215513512495] [Medline: 24293120]

26. Dias AE, Limongi JCP, Hsing WT, Barbosa ER. Telerehabilitation in Parkinson's disease: Influence of cognitive status. Dement Neuropsychol 2016;10(4):327-332 [FREE Full text] [doi: 10.1590/s1980-5764-2016dn1004012] [Medline: 29213477]

27. Gandolfi M, Geroin C, Dimitrova E, Boldrini P, Waldner A, Bonadiman S, et al. Virtual Reality Telerehabilitation for Postural Instability in Parkinson's Disease: A Multicenter, Single-Blind, Randomized, Controlled Trial. Biomed Res Int 2017;2017:7962826. [doi: 10.1155/2017/7962826] [Medline: 29333454]

28. Constantinescu G, Theodoros D, Russell T, Ward E, Wilson S, Wootton R. Assessing disordered speech and voice in Parkinson's disease: a telerehabilitation application. Int J Lang Commun Disord 2010;45(6):630-644. [doi: 10.3109/13682820903470569] [Medline: 20102257]

29. Finkelstein J, Liu J. Usability of Telerehabilitation System Supporting Multipronged Exercise in Patients with Multiple Sclerosis. Stud Health Technol Inform 2018;251:281-284. [Medline: 29968658]

30. Khan F, Amatya B, Kesselring J, Galea MP. Telerehabilitation for persons with multiple sclerosis. A Cochrane review. Eur J Phys Rehabil Med 2015 Jun;51(3):311-325 [FREE Full text] [Medline: 25943744]

31. Tousignant M, Boissy P, Corriveau H, Moffet H, Cabana F. In-home telerehabilitation for post-knee arthroplasty: a pilot study. Int J Telerehabil 2009;1(1):9-16 [FREE Full text] [doi: 10.5195/ijt.2009.5997] [Medline: 25945158]

32. Tousignant M, Moffet H, Boissy P, Corriveau H, Cabana F, Marquis F. A randomized controlled trial of home telerehabilitation for post-knee arthroplasty. J Telemed Telecare 2011;17(4):195-198. [doi: 10.1258/jtt.2010.100602] [Medline: 21398389]

33. O'Moore KA, Newby JM, Andrews G, Hunter DJ, Bennell K, Smith J, et al. Internet Cognitive-Behavioral Therapy for Depression in Older Adults With Knee Osteoarthritis: A Randomized Controlled Trial. Arthritis Care Res (Hoboken) 2018 Jan;70(1):61-70. [doi: 10.1002/acr.23257] [Medline: 28426917]

34. Huang Z, Zhong X, Xie Z, Li T. The feasibility and effectiveness of telemedicine for knee osteoarthritis in disease management: A randomised control trial. In: Ann Rheum Dis (Supplement 2). 2019 Presented at: Annual European Congress of Rheumatology (EULAR); June 12-15, 2019; Madrid, Spain. [doi: 10.1136/annrheumdis-2019-eular.6474]

35. Allen K, Arbeeva L, Callahan L, Golightly Y, Goode A, Heiderscheit B, et al. Physical therapy vs internet-based exercise training for patients with knee osteoarthritis: results of a randomized controlled trial. Osteoarthritis Cartilage 2018 Mar;26(3):383-396 [FREE Full text] [doi: 10.1016/j.joca.2017.12.008] [Medline: 29307722]

36. Kloek CJJ, Bossen D, Spreeuwenberg PM, Dekker J, de Bakker DH, Veenhof C. Effectiveness of a Blended Physical Therapist Intervention in People With Hip Osteoarthritis, Knee Osteoarthritis, or Both: A Cluster-Randomized Controlled Trial. Phys Ther 2018 Jul 01;98(7):560-570 [FREE Full text] [doi: 10.1093/ptj/pzy045] [Medline: 29788253]

37. Moher D, Liberati A, Tetzlaff J, Altman DG, PRISMA Group. Preferred reporting items for systematic reviews and meta-analyses: the PRISMA statement. BMJ 2009 Jul 21;339:b2535 [FREE Full text] [doi: 10.1136/bmj.b2535] [Medline: 19622551]

38. Booth A, Clarke M, Dooley G, Ghersi D, Moher D, Petticrew M, et al. The nuts and bolts of PROSPERO: an international prospective register of systematic reviews. Syst Rev 2012 Feb 09;1:2 [FREE Full text] [doi: 10.1186/2046-4053-1-2] [Medline: 22587842]

39. Guyatt GH, Oxman AD, Kunz R, Atkins D, Brozek J, Vist G, et al. GRADE guidelines: 2. Framing the question and deciding on important outcomes. J Clin Epidemiol 2011 Apr;64(4):395-400. [doi: 10.1016/j.jclinepi.2010.09.012] [Medline: 21194891]

40. Altman R, Alarcón G, Appelrouth D, Bloch D, Borenstein D, Brandt K, et al. The American College of Rheumatology criteria for the classification and reporting of osteoarthritis of the hip. Arthritis Rheum 1991 May;34(5):505-514. [doi: 10.1002/art.1780340502] [Medline: 2025304]

41. Altman R, Asch E, Bloch D, Bole G, Borenstein D, Brandt K, et al. Development of criteria for the classification and reporting of osteoarthritis. Classification of osteoarthritis of the knee. Diagnostic and Therapeutic Criteria Committee of the American Rheumatism Association. Arthritis Rheum 1986 Aug;29(8):1039-1049. [doi: 10.1002/art.1780290816] [Medline: 3741515]

42. Maher CG, Sherrington C, Herbert RD, Moseley AM, Elkins M. Reliability of the PEDro scale for rating quality of randomized controlled trials. Phys Ther 2003 Aug;83(8):713-721. [Medline: 12882612] 
43. de Morton NA. The PEDro scale is a valid measure of the methodological quality of clinical trials: a demographic study. Aust J Physiother 2009;55(2):129-133. [doi: 10.1016/s0004-9514(09)70043-1] [Medline: 19463084]

44. Verhagen AP, de Vet HC, de Bie RA, Kessels AG, Boers M, Bouter LM, et al. The Delphi list: a criteria list for quality assessment of randomized clinical trials for conducting systematic reviews developed by Delphi consensus. J Clin Epidemiol 1998 Dec;51(12):1235-1241. [doi: 10.1016/s0895-4356(98)00131-0] [Medline: 10086815]

45. Foley NC, Bhogal SK, Teasell RW, Bureau Y, Speechley MR. Estimates of quality and reliability with the physiotherapy evidence-based database scale to assess the methodology of randomized controlled trials of pharmacological and nonpharmacological interventions. Phys Ther 2006 Jun;86(6):817-824. [Medline: 16737407]

46. PEDro scale. PEDro: Physiotherapy Evidence Database. URL: https://pedro.org.au/english/resources/pedro-scale/ [accessed 2020-03-01]

47. PEDro, The Physiotherapy Evidence Database. URL: https://pedro.org.au/ [accessed 2020-03-01]

48. Cumpston M, Li T, Page MJ, Chandler J, Welch VA, Higgins JP, et al. Updated guidance for trusted systematic reviews: a new edition of the Cochrane Handbook for Systematic Reviews of Interventions. Cochrane Database Syst Rev 2019 Oct 03;10:ED000142. [doi: 10.1002/14651858.ED000142] [Medline: 31643080]

49. Higgins JPT, Thompson SG, Deeks JJ, Altman DG. Measuring inconsistency in meta-analyses. BMJ 2003 Sep 06;327(7414):557-560 [FREE Full text] [doi: 10.1136/bmj.327.7414.557] [Medline: 12958120]

50. Cochrane Handbook for Systematic Reviews of Interventions. Cochrane Training. URL: https://training.cochrane.org/ handbook/current [accessed 2020-03-03]

51. Rini C, Porter LS, Somers TJ, McKee DC, DeVellis RF, Smith M, et al. Automated Internet-based pain coping skills training to manage osteoarthritis pain: a randomized controlled trial. Pain 2015 May;156(5):837-848 [FREE Full text] [doi: 10.1097/j.pain.0000000000000121] [Medline: 25734997]

52. Aily J, Castilho de Almeida A, da Silva Ribeiro G, de Noronha M, Mattiello S. Is a periodized circuit training delivered by telerehabilitation effective for patients with knee osteoarthritis? a phase i randomized controlled trial. In: Osteoarthritis and Cartilage. 2020 Apr Presented at: OARSI World Congress on Osteoarthritis - Promoting Clinical and Basic Research in Osteoarthritis; April 30-May 3, 2020; Vienna, Austria p. S468-S469. [doi: 10.1016/j.joca.2020.02.734]

53. Bossen D, Veenhof C, Van Beek KE, Spreeuwenberg PM, Dekker J, De Bakker DH. Effectiveness of a web-based physical activity intervention in patients with knee and/or hip osteoarthritis: randomized controlled trial. J Med Internet Res 2013 Nov 22;15(11):e257 [FREE Full text] [doi: 10.2196/jmir.2662] [Medline: 24269911]

54. Fitzgerald GK, Hinman RS, Zeni J, Risberg MA, Snyder-Mackler L, Bennell KL. OARSI Clinical Trials Recommendations: Design and conduct of clinical trials of rehabilitation interventions for osteoarthritis. Osteoarthritis Cartilage 2015 May;23(5):803-814 [FREE Full text] [doi: 10.1016/j.joca.2015.03.013] [Medline: 25952351]

55. Armijo-Olivo S, Fuentes J, da Costa BR, Saltaji H, Ha C, Cummings GG. Blinding in Physical Therapy Trials and Its Association with Treatment Effects: A Meta-epidemiological Study. Am J Phys Med Rehabil 2017 Jan;96(1):34-44. [doi: 10.1097/PHM.0000000000000521] [Medline: 27149591]

56. Ackerman I. Western Ontario and McMaster Universities Osteoarthritis Index (WOMAC). Aust J Physiother $2009 ; 55(3): 213$. [doi: 10.1016/s0004-9514(09)70088-1] [Medline: 19736686]

57. Meenan RF, Mason JH, Anderson JJ, Guccione AA, Kazis LE. AIMS2. The content and properties of a revised and expanded Arthritis Impact Measurement Scales Health Status Questionnaire. Arthritis Rheum 1992 Jan;35(1):1-10. [doi: 10.1002/art.1780350102] [Medline: $\underline{1731806}$ ]

58. Roos EM, Roos HP, Lohmander LS, Ekdahl C, Beynnon BD. Knee Injury and Osteoarthritis Outcome Score (KOOS)--development of a self-administered outcome measure. J Orthop Sports Phys Ther 1998 Aug;28(2):88-96. [doi: 10.2519/jospt.1998.28.2.88] [Medline: 9699158]

59. Collins NJ, Hart HF, Mills KAG. Osteoarthritis year in review 2018: rehabilitation and outcomes. Osteoarthritis Cartilage 2019 Mar;27(3):378-391 [FREE Full text] [doi: 10.1016/j.joca.2018.11.010] [Medline: 30529739]

60. Allen KD, Arbeeva L, Callahan LF, Golightly YM, Goode AP, Heiderscheit BC, et al. Physical therapy vs internet-based exercise training for patients with knee osteoarthritis: results of a randomized controlled trial. Osteoarthritis Cartilage 2018 Mar;26(3):383-396 [FREE Full text] [doi: 10.1016/j.joca.2017.12.008] [Medline: 29307722]

61. Bennell KL, Nelligan RK, Rini C, Keefe FJ, Kasza J, French S, et al. Effects of internet-based pain coping skills training before home exercise for individuals with hip osteoarthritis (HOPE trial): a randomised controlled trial. Pain 2018 Sep;159(9):1833-1842. [doi: 10.1097/j.pain.0000000000001281] [Medline: 29794609]

62. Wang X, Hunter DJ, Vesentini G, Pozzobon D, Ferreira ML. Technology-assisted rehabilitation following total knee or hip replacement for people with osteoarthritis: a systematic review and meta-analysis. BMC Musculoskelet Disord 2019 Nov 03;20(1):506 [FREE Full text] [doi: 10.1186/s12891-019-2900-x] [Medline: 31679511]

63. Schäfer AGM, Zalpour C, von Piekartz H, Hall TM, Paelke V. The Efficacy of Electronic Health-Supported Home Exercise Interventions for Patients With Osteoarthritis of the Knee: Systematic Review. J Med Internet Res 2018 Apr 26;20(4):e152 [FREE Full text] [doi: 10.2196/jmir.9465] [Medline: 29699963] 


\section{Abbreviations}

AIMS2: Arthritis Impact Measurement Scale 2

IBET: internet-based exercise training

iCBT: internet cognitive behavior therapy

KOOS: Knee Injury and Osteoarthritis Outcome Score

NPRS: Numeric Pain Rating Scale

OA: osteoarthritis

PEDro: Physiotherapy Evidence Database

RCT: randomized controlled trial

SMD: standardized mean difference

TUG: The Timed Up and Go Test

VAS: The visual analog scale

WOMAC: The Western Ontario and McMaster Universities Osteoarthritis

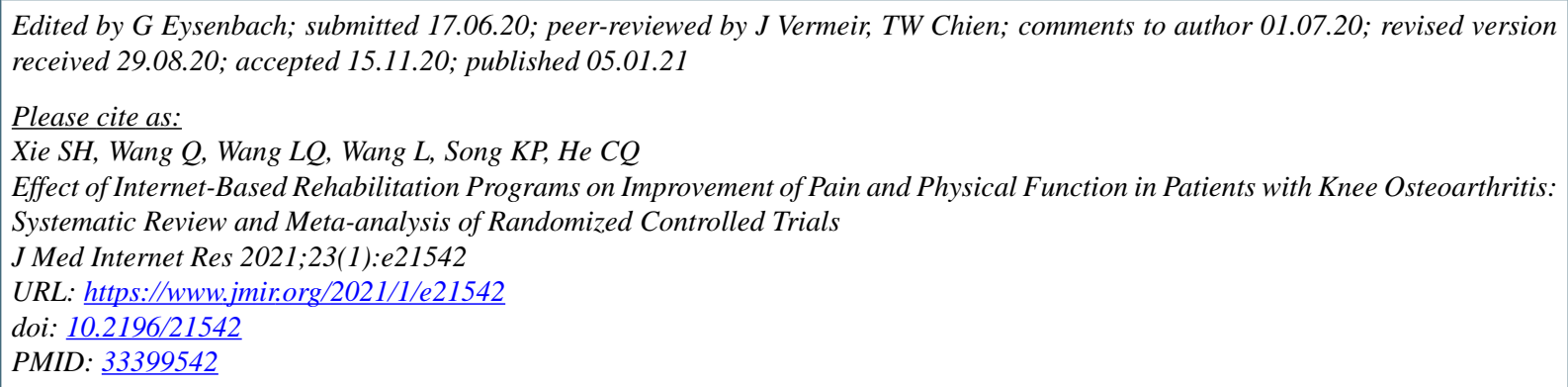

CSu-Hang Xie, Qian Wang, Li-Qiong Wang, Lin Wang, Kang-Ping Song, Cheng-Qi He. Originally published in the Journal of Medical Internet Research (http://www.jmir.org), 05.01.2021. This is an open-access article distributed under the terms of the Creative Commons Attribution License (https://creativecommons.org/licenses/by/4.0/), which permits unrestricted use, distribution, and reproduction in any medium, provided the original work, first published in the Journal of Medical Internet Research, is properly cited. The complete bibliographic information, a link to the original publication on http://www.jmir.org/, as well as this copyright and license information must be included. 